NASA Technical Memorandum 105337

\title{
An Evaluation of Strain Measuring Devices for Ceramic Composites
}

John Z. Gyekenyesi

Cleveland State University

Cleveland, Ohio

and

Paul A. Bartolotta

Lewis Research Center

Cleveland, Ohio 


\title{
AN EVALUATION OF STRAIN MEASURING
}

\section{DEVICES FOR CERAMIC COMPOSITES}

\author{
John Z. Gyekenyesi* \\ Cleveland State University \\ Civil Engineering Department \\ Cleveland, Ohio 44115 \\ Paul A. Bartolotta \\ National Aeronautics and Space Administration \\ Lewis Research Center \\ Cleveland, Ohio 44135
}

*Resident Research Associate at NASA Lewis Research Center 


\section{ABSTRACT}

A series of tensile tests were conducted on SiC/RBSN composites using different methods of strain measurement. The tests were used to find the optimum strain sensing device for use with continuous fiber reinforced ceramic matrix composites in ambient and high temperature environments. Bonded resistance strain gages were found to offer excellent performance for room temperature tests. The clip-on gage offers the same performance but significantly less time is required for mounting it to the specimen. Low contact force extensometers track the strain with acceptable results at high specimen temperatures. Silicon carbide rods with knife edges are preferred. The edges must be kept sharp. The strain measuring devices should be mounted on the flat side of the specimen. This is in contrast to mounting on the rough thickness side.

\section{INTRODUCTION}

High temperature tensile testing of ceramic composites presents many new and unique problems to today's experimentalist. One of the most important challenges involves the real-time monitoring of strain in a tensile specimen. Presently, our focus is to test ceramic composite coupons at temperatures approaching $1550^{\circ} \mathrm{C}\left(2800^{\circ} \mathrm{F}\right)$ in air and up to $1750^{\circ} \mathrm{C}\left(3200^{\circ} \mathrm{F}\right)$ in inert environments. These composites have unidirectional continuous fiber reinforcement. Research has been initiated to develop testing methods for evaluating these advanced composite systems, especially in the area of high temperature tensile testing (refs. 1 and 2). These efforts have included literature searches, personal communications with other researchers, and evaluations of commercially available equipment.
The average magnitude of strain to failure in ceramics is only a fraction of that in metals or other ductile materials. This requires the use of strain gages with fine resolution. In addition, ceramics are very hard and sensitive to stress concentrations making it difficult to use contact type strain measuring devices. These properties preclude notching the specimen surface for the extensometer rods.

A few commercially available strain measuring devices have been developed for use under these harsh conditions. This includes mechanical and optical extensometers. Flags for an optical strain extensometer are difficult to retain or do not stay in a single plane when a composite is well beyond first matrix cracking. As a result, some researchers who had been using an optical technique for measuring strain have switched to the mechanical extensometers (ref. 3). However, optical extensometers have been successfully utilized for creep testing of monolithic ceramics (ref. 4,5).

This paper describes selected tests utilizing various strain measuring devices in the tensile testing of unidirectional silicon carbide fiber reinforced reaction bonded silicon nitride ( $\mathrm{SiC} / \mathrm{RBSN}$ ) composites. Room temperature tests were used to compare results from bonded strain gages, clip-on gages, three different mechanical extensometers, and a laser extensometer. Bonded strain gages were used as the reference strain measuring devices for room temperature tensile tests, because extensive SiC/RBSN strength data were previously obtained using these bonded strain gages (refs. $6,7)$. For the high temperature tests, the mechanical and laser extensometers were used at a specimen temperature of approximately $1000^{\circ} \mathrm{C}\left(1800^{\circ} \mathrm{F}\right)$ in air.

Results from these tests were evaluated to determine the optimum type of strain measuring device for SiC/RBSN composites. Issues of 
concern included determining the modulus in the linear region of the stress/strain diagram, measuring the strain at first matrix cracking or deviation from linearity, and monitoring the strain to ultimate strength. Accurate measurement of strain after first matrix cracking is of particular concern. As multiple matrix cracks form in the SiC/RBSN composite, there is a sudden release of energy which can result in slipping of contact extensometers or dislodging of flags when optical extensometers are used. In some cases, the flags or contact extensometers can cause enough of a stress concentration to initiate localized matrix damage. Contact extensometers can also induce significant bending in the specimen.

On the subject of bending, the authors realize the importance of monitoring the strain on opposite sides of the specimen. All the room temperature tests could accommodate strain gages on either side of the specimen so that specimen bending could be determined. Unfortunately, the high temperature tests were limited to the use of one strain measuring device due to limited access to the specimen through the furnace. Room temperature tests in the past with the SiC/RBSN composites have shown bending to be less than $5 \%$ at first matrix cracking. It is realized that heating a composite can induce additional bending due to non-symmetry within the specimen, but the use of one strain gage was considered to be an acceptable compromise for the high temperature tensile tests. Future modifications may include a second strain gage if it is found to be feasible.

The various strain measuring devices have different size gage sections. The differences in strain output using the different gage sections will be investigated and explained. A description of the equipment for these tests is provided in the next section. Figure 1 illustrates the testing system used for these tests. The different types of equipment used for these tests are representative of what is available commercially. Many manufacturers offer comparable instruments to the ones used here.

\section{EQUIPMENT}

1. Frame

Al1 tests were conducted on a universal tensile testing machine. The unit has an 89 kilonewton (20,000 pounds) electric actuator. It is fully digitally controlled, making closed-loop control with load, strain, or crosshead displacement possible.

Mechanical wedge grips were utilized for the room temperature tensile tests when testing was initiated. The grips were mounted within a rigid load train without any self alignment fixtures. These mechanical wedge grips were used in all tests with clip-on gages, one of the mechanical extensometers, and the laser extensometer. A compact water cooled pneumatic wedge grip was used for the rest of the ambient and all high temperature tests. These grips were attached to a hydraulic alignment device. The hydraulic alignment device is the same unit illustrated in references 8 and 9 . The pneumatic grips with the alignment device can be observed in Figure 1. Both sets of grips used serrated grip faces with $1.6 \mathrm{milli-}$ meter tooth spacing (16 teeth per inch) in a diamond pattern. The mechanical wedge grips were used until the pneumatic grips were available.

\section{Furnace}

The furnace used for the high temperature tests is of a slotted configuration. This design allows the furnace to remain hot throughout the testing procedure, including the time during specimen changes. The 
furnace is mounted on rails so that it can be drawn around the test coupon once it has been mounted in the grips. The furnace is shown mounted in the test system in Figure 1. An insulating plug is inserted in the slot of the furnace when it contains the specimen. The hot section is relatively short, being 100 millimeters ( 4 inches) long. It has two heating zones using molybdenum disilicide elements. Maximum specimen temperature is approximately $1550^{\circ} \mathrm{C}\left(2800^{\circ} \mathrm{F}\right)$. The maximum specimen temperature is held to $\pm 2{ }^{\circ} \mathrm{C}$ within a 25 millimeter ( 1 inch) gage section according to the manufacturer's specification. Thermocouples were used to monitor element, specimen, and grip temperatures. Sapphire windows are placed in the back and front of the furnace for use with laser extensometers. The centerline of the windows is offset by 5 millimeters ( 0.20 inches) from the centerline of the furnace. When mechanical extensometers were used in the tests, the front plug with the window was removed from the furnace and replaced with a plug containing open ports.

\section{Laser Extensometer}

The laser extensometer has a transmitter mounted on the front of the frame and a receiver mounted on the back. The units are tied together with a digital processor. The transmitter consists of a scanning laser. The laser is mounted such that the plane of the scanning laser intersects the flags mounted on the specimen surface. The laser light and the shadows from the flags are monitored by the receiver. A schematic diagram of the system is illustrated in Figure 2. The processor is programmed to track the motion of the inner edges of the flags. The laser beam scans at a rate of 150 scans per second. The processor is set up to average a user defined number of scans. Additional information on settings is provided in the section dealing with the testing procedure. Table I contains some of the manufacturer's specifications for the laser device.

TABLE I:

LASER EXTENSOMETER SPECIFICATIONS

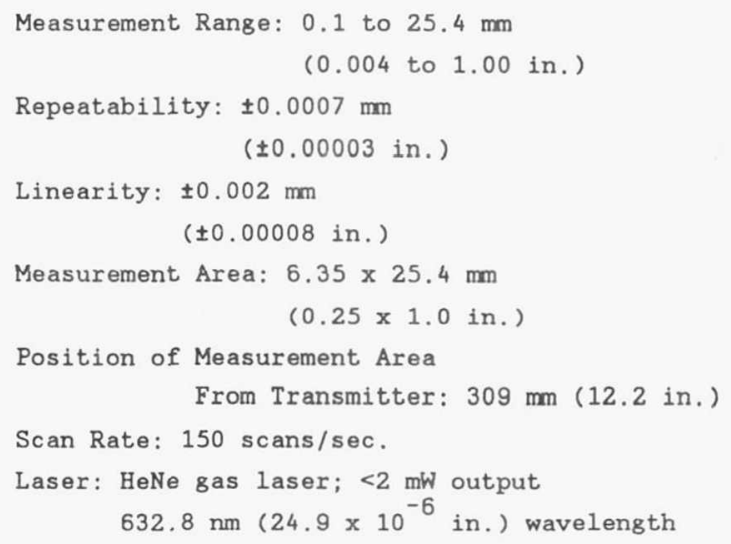

4. Mechanical Extensometer, Full Bridge Resistance Gage

This mechanical extensometer is for high temperature applications. It is water cooled. The unit uses four strain gages mounted in a full Wheatstone bridge. Quartz rods with V-chisel edges were used for our tests. Table II shows the manufacturer's specifications for this extensometer. The rods apply a force of 350 grams ( 0.772 pounds) per rod.

TABLE II

MECHANICAL EXTENSOMETER, FULL BRIDGE RESISTANCE GAGE

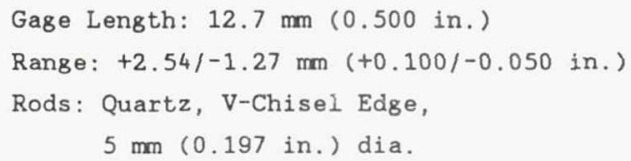

5. Mechanical Extensometer, Capacitive

The capacitive mechanical extensometer uses a variable capacitor to convert displacements into 
electrical signals. This unit was set up for high temperature applications. It had silicon carbide rods with knife edges. The body of the extensometer was air cooled. Figure 1 shows the extensometers mounted in the testing system. The manufacturer's specifications are presented in Table III.

\section{TABLE III}

\section{CAPACITIVE MECHANICAL EXTENSOMETER}

Gage Length: $25 \mathrm{~mm}$ (0.984 in.)

Gage Length Accuracy: $\pm 0.05 \mathrm{~mm}( \pm 0.002 \mathrm{in.})$ Gage Length Repeatability: $\pm 0.01 \mathrm{~mm}( \pm 0.0004 \mathrm{in.})$ Strain Range: $0.04 \mathrm{~mm} / \mathrm{mm}$ ( $0.04 \mathrm{in.} / \mathrm{in}$.)

Displacement Range: $\pm 1.0 \mathrm{~mm}( \pm 0.04 \mathrm{in}$.)

Output Sensitivity: $40 \mathrm{v} / \mathrm{mm}(1000 \mathrm{~V} / \mathrm{in}$.

Temperature Range, Specimen: Ambient to $1600^{\circ} \mathrm{C}$ (Ambient to $2900^{\circ} \mathrm{F}$ )

Contact Force: 0 to 100 grams ( 0 to 3.5 ounces)

Rods: Silicon carbide, knife edge

6. Mechanical Extensometer, Low Contact Force, Full Bridge Resistance Gage

The low contact force extensometer is a relatively new unit. This unit can be setup with different springs to vary the contact force of each rod on the specimen. In our tests the springs were setup for 100 grams per rod and 350 grams per rod. This extensometer uses four resistance strain gages mounted in a Wheatstone bridge like the other mechanical extensometer described in this section. The gage section was 12.7 millimeters ( 0.5 inches). Table IV presents specifications for this unit. The extensometer body and heat shield are water cooled.

TABLE IV:

MECHANICAL EXTENSOMETER, LOW CONTACT FORCE, FULL BRIDGE RESISTANCE GAGE

Gage Length: $12.7 \mathrm{~mm}(0.500$ in. )

Rods: Vistal Ceramic, V-Chisel Edge, $5 \mathrm{~mm}(0.197 \mathrm{in.})$ dia.
Contact Force: 100 grams per rod or 350 grams per rod

Strain Range: $\pm 20 \%$

Displacement Range: $\pm 2.5 \mathrm{~mm}( \pm 0.100 \mathrm{in.})$

Bridge Resistance: 1000 ohms

Excitation: $6.0 \mathrm{~V}$

\section{Clip-On Gage}

The clip-on gage worked in conjunction with the frame's electronic controls. A built in resistor was used to make it self-identifying to the frame's controls. As a result, the frame's controls were used to electronically calibrate the gage and process its output signal. The gage has a 12.7 millimeter $(0.5$ inch) gage section. When a 12.7 millimeter ( 0.5 inch) extension was used a 25.4 millimeter ( 1.0 inch) gage section was obtained for this extensometer. The maximum extension with this extensometer is \pm 2.5 millimeters ( \pm 0.10 inches). This results in a maximum strain of 10000 $\mu$ strain. Specifications are presented in Table $V$. The extensometer was held to the test coupon with small rubber bands which were supplied with the gage.

TABLE V:

CLIP-ON GAGE

Gage Length: $25.4 \mathrm{~mm}$. (1.0 in.) with extension

Range: $\pm 2.5 \mathrm{~mm} .( \pm 0.10 \mathrm{in.})$

Output Sensitivity: $3.0 \mathrm{MV} / \mathrm{V} \pm 10 \%$

Bridge Resistance: 350 ohms

Excitation: $5 \mathrm{~V}$ nominal

\section{Bonded Resistance Strain Gages}

Commercial resistance strain gages were employed for all room temperature tensile tests. These were general purpose constantan strain gages backed by a 0.03 millimeter (0.001 inch) thick, tough, flexible polyimide film. All the gages had a $120 \mathrm{ohm}$ resistance. The gage sections were either $3.2 \mathrm{milli}$ - 
meters ( 0.125 inch) or 6.4 millimeters $(0.25$ inch). Table VI presents the manufacturer's specifications for the bonded strain gages.

A methyl-cyanoacrylate based adhesive with a trichloroethane catalyst was used to bond the strain gages to the surface of the specimen.

TABLE VI:

BONDED RESISTANCE STRAIN GAGES

\section{1. $3.2 \mathrm{~mm}$ gage section}

Foil Alloy: constantan

Self-Temperature Compensation: $3 \mu$ strain $/{ }^{\circ} \mathrm{F}$

Gage Section: $3.2 \mathrm{~mm}$ (0.125 inch)

Resistance: $120.0 \pm 0.15 \% \Omega \& 24^{\circ} \mathrm{C}\left(75^{\circ} \mathrm{F}\right)$

Gage Factor: $2.045 \pm 0.5 \%$ \& $24^{\circ} \mathrm{C}\left(75^{\circ} \mathrm{F}\right)$

Transverse Sensitivity: $+1.1 \pm 0.2 \%$

Strain Limits: $\sim 5 \%$

\section{2. $6.4 \mathrm{~mm}$ gage section}

Foil Alloy: constantan

Self-Temperature Compensation: $3 \mu$ strain $/{ }^{\circ} \mathrm{F}$

Gage Section: $6.4 \mathrm{~mm}$ (0.250 inch)

Resistance: $120.0 \pm 0.15 \% \Omega \& 24^{\circ} \mathrm{C}\left(75^{\circ} \mathrm{F}\right)$

Gage Factor: $2.035 \pm 0.5 \% \odot 24^{\circ} \mathrm{C}\left(75^{\circ} \mathrm{F}\right)$

Transverse Sensitivity: $+0.9 \pm 0.2 \%$

Strain Limits: $\sim 5 \%$

\section{RECORDERS}

Load and strain outputs were recorded on analog two pen X-Y recorders. Load signals from the frame were processed through an optical isolator during high temperature tests to reduce some of the signal noise.

\section{TEST SPECIMEN CONFIGURATION}

The specimen material consisted of approximately 24 volume percent, uniaxially aligned, 142 micron $(5.6 \mathrm{mils}) \mathrm{SiC}$ fibers with a reaction bonded silicon nitride matrix. The fibers were chemical vapor deposited silicon carbide on a carbon core. The fibers had a carbon coating on the outer surface to form an interface with the matrix material. A more detailed description of the material and processing is given in reference 6 . It should be noted that this composite system is in the development stages. The composite is being developed at Lewis Research Center for high temperature engine applications .

The composite specimens were flat, constant thickness, straight sided coupons with bonded tabs on either end. Glass fiber/epoxy composite tabs were used for all room temperature tests. Carbon fiber/polyimide composite tabs and aluminum tabs were utilized in high temperature tests. The tabs were bonded to the specimen using structural film adhesives. For room temperature tests, specimen length was 114 millimeters ( 4.5 inches). On the other hand, the length was 203 millimeters ( 8.0 inches) for all high temperature tests. The lengths for high temperature tests were dictated by the furnace height. In addition, the area near the grips had to be kept at low enough temperatures to allow use of compliant polymer based tabs. The specimen width was 13 millimeters (0.5 inches) for all tests. The thickness was approximately 2.3 millimeters (0.09 inches). The tensile coupons were cut from a panel with a diamond impregnated abrasive wheel. There was no attempt to seal the exposed fibers on the cut surfaces of the specimens.

The specimen geometry was derived from the American Society for Testing and Materials (ASTM) Designation: D 3039-76 (ref. 10). This standard geometry is shown in Figure 3. This is the standard test method for tensile properties of fiber-resin composites. This configuration has been used successfully in the past under ambient conditions. The failures occur within the gage section.

The carbon fiber/polyimide 
composite tabs were shortened to 32 millimeters ( 1.25 inches) relative to the ASTM standard of 38 millimeters ( 1.5 inches). The longer tabs protruded past the grips allowing the material to spontaneously combust when testing at high temperatures. All the tabs were 13 millimeters ( 0.5 inches) wide and 1.5 millimeters (0.060 inches) thick.

\section{PROCEDURE}

The strain measuring devices used for these tests were readily available from commercial suppliers. Due to the limited availability of the ceramic composite specimens, only two to seven coupons were used with each of the strain measuring devices.

The clip-on gages, mechanical extensometers, and laser extensometers were tested individually with one device per specimen for all the tests. All the room temperature tests had bonded resistance strain gages on either side of the tensile coupons, in addition to the above mentioned strain measuring devices, to monitor the mean and bending strains. All the strain measuring devices were attached to the flat side of the samples, shown in Figure $4 \mathrm{~A}$, except in two tests with a couple of mechanical extensometers. The mechanical extensometers with full bridge resistance gages contacted the test coupon on the thickness side as illustrated in Figure 4B. The specimen surface was not notched for the mechanical extensometers. The flags for the laser extensometers were bonded with an alumina based ceramic adhesive to the surface of the sample for high temperature tests. A cyanoacrylate ester based adhesive was used to bond the flags to the specimen for room temperature tests. The flags used with the laser extensometer consisted of alumina rods with a diameter of 1.6 millimeters $(0.062$ inches).
Bonded resistance strain gages were set up in a quarter bridge with signal conditioners. The excitation voltage was set at 2.0 volts. The conditioner output was calibrated such that 10 volts corresponded to 1.0 percent strain.

Tests were performed on a universal digitally controlled tensile testing frame with an electric actuator. They were conducted in the displacement control mode which provides a constant crosshead rate. The crosshead rate was varied from a low of $0.051 \mathrm{~mm} / \mathrm{min}$. (0.002 in./min.) for laser extensometers to $1.27 \mathrm{~mm} / \mathrm{min}$. (0.05 in./min.) for mechanical extensometers.

As mentioned earlier, the laser extensometer uses a scanning laser. The scanning rate is 150 scans per second. The processor was setup to average 150 to 300 scans for each data point. The slow rate of output from the laser extensometer was the reason for the slow crosshead rate of $0.051 \mathrm{~mm} / \mathrm{min}$. (0.002 in./min.). The output was calibrated such that 10 volts corresponded to 0.5 \& strain.

A11 the mechanical extensometers were calibrated such that 10 volts corresponded to 1 \& strain. The clip-on gage was calibrated such that 10 volts corresponded to 10 \% strain.

The furnace was brought up to the desired temperature before testing began for all high temperature tests. Once the specimen was loaded into the grips, the furnace was pulled forward around the sample. At the same time the mechanical extensometer was inserted into the hot zone without contacting the specimen. Once the test coupon temperature stabilized, the extensometer was brought into contact with the sample and the tensile test was initiated. When using the laser extensometer, the instrument was setup to measure the length of the gage section. Once the specimen temperature had stabilized, the gage section length was entered into the 
processor such that the output would consist of the calculated average strain. In addition, the frame was kept in load control such that the sample was under no load while it was being brought up in temperature. The frame was placed into displacement control when the sample temperature stabilized.

Al1 the output was recorded with analog two pen $X-Y$ recorders. Points were manually read off the plots and the desired material properties were calculated. The modulus was determined by visually fitting a line through the linear region of the load/strain plot and calculating the modulus from the slope.

\section{RESULTS AND DISCUSSION}

Composite stiffness and strength properties are presented here as calculated from the output of various strain measuring devices. Specimens from room temperature tests showed less than 58 bending at first matrix cracking. This was determined using the following equation:

$\%$ bending $=\frac{\epsilon_{1}-\epsilon_{2}}{\epsilon_{1}+\epsilon_{2}} \times 100$

where: $\epsilon_{1}=$ strain from first bonded strain gage

$\epsilon_{2}=$ strain from second

The first and second bonded strain gages were mounted on opposite sides in the middle of the flat side of the specimen. Table VII contains room temperature tensile properties from tests conducted with the various strain measuring devices including the bonded resistance strain gages. Table VIII contains tensile properties from tests with the specimen gage section held at $1000^{\circ} \mathrm{C}$ $\left(1830^{\circ} \mathrm{F}\right)$. The high temperature data was generated using the capacitive mechanical extensometer and the low contact force mechanical extensometer with the full bridge resistance gage. This data represents typical stiffness and strength properties of unidirectional SiC/RBSN coupons having various fiber fractions and matrix properties. The objective was to compare data from the strain measuring devices and not to obtain ceramic matrix composite (CMC) design data. Table VII also includes the number of scans that were averaged by the laser extensometer processor for each data point.

1. Bonded Resistance Strain Gages, Room Temperature

The output from the bonded resistance strain gages, which were used for all room temperature tests, exhibited a very steady signal. The elastic region of the stress/strain curves were straight with no oscillations. Any noise was below the resolution of the X-Y plotters that were used for our tests. The effects of the small gage section were apparent only after extensive matrix cracking has occurred. As cracks formed, the strain gage sometimes showed a decrease in strain. This was due to the fact that the part of the matrix that the strain gage was bonded to unloaded partially. Near the ultimate strength the matrix can actually be free floating resulting in little or no strain output.

The strain signals from the bonded strain gages were monitored relative to time with specimen number 557-2. The strain rate was $0.045 \% / \mathrm{min}$.

2. Laser Extensometer, Room Temperature

The maximum strain that can be measured by the laser extensometer was $0.5 \%$ as mentioned earlier. As a result, data obtained from some specimens exceeded the maximum measurable strain. The coupons 
tended to break at approximately $0.6 \%$ strain. We were more interested in the region of the stress/strain curve before the ultimate strength.

The laser extensometer drifted within a $350 \mu$ strain range about a mean strain when 300 scans were averaged. Decreasing the number of scans averaged to 250 or even 150 did not change the drifting significantly relative to averaging 300 scans. The crosshead speed was 0.051 $\mathrm{mm} / \mathrm{min}$. (0.002 in./min.) for all the tests with the laser extensometer. The resulting strain rate was 450 $\mu$ strain/min. which was derived from one of the bonded strain gage outputs. We can calculate the specimen strain increment over which the laser extensometer averages each data point. At 150 scans per second and averaging 150 scans we get a data point once every second. In that time the sample was strained 8 $\mu$ strain as noted in the results. In this case the laser extensometer averaged its reading over 0.0008 \& strain in the sample. Averaging 300 scans results in a specimen strain increment of $15 \mu$ strain over which the laser extensometer averages its data points. It can be seen from these calculations and the data in Table VII that a slow strain rate and a low number of scans averaged is desirable with the laser extensometer to get a reasonably accurate strain output.

The laser extensometer has a tendency to miss some of the strain readings once in a while resulting in a zero strain output at that point on the stress/strain curve. This has been observed by other researchers (ref. 11) using this laser extensometer. It should be noted that for a computerized data acquisition system these zero readings would have to be accommodated. During matrix cracking the output from the extensometer becomes slightly random within a narrow range about a point. This has to be observed by a user and marked separately on the output plot. If that point is not marked then it becomes difficult to pick it out later because it tends to blend with the normal oscillations. In addition, it is difficult to determine where the change in slope occurs. The output from the laser extensometer exhibited a small amplitude, large wavelength, sinusoidal curve within the linear portion of the stress strain curve for most of the room temperature tests. One of these stress/strain curves is presented in Figure 5. Referring to Table VII, the test with specimen number 554-2 showed the best correlation between the laser extensometer and the bonded strain gage output. This test had 150 scans averaged per data point for the laser extensometer. The laser extensometer showed a 0.01 greater strain than the bonded strain gage. There was a 1.08 difference in moduli relative to the bonded strain gage. Increasing the number of scans averaged seemed to introduce greater discrepancies in the strain values and moduli. This is due to the larger specimen strain increment over which the extensometer averages its readings for a data point.

\section{Clip-On Gage, Room Temperature}

The clip-on gage used in these tests was tested at room temperature only as it is not designed for high temperature applications. The clipon gage was mounted on the flat side of the specimen for all the tests. The output from the clip-on gage was nearly identical to the output from the bonded resistance strain gages within the linear region of the stress/strain curve. The clip-on gage showed the same noise free output. The material properties were calculated using each gage and are shown in Table VII. The moduli were nearly identical. The test with specimen number 550-4 showed the effects of different gage lengths once matrix cracking was initiated. 


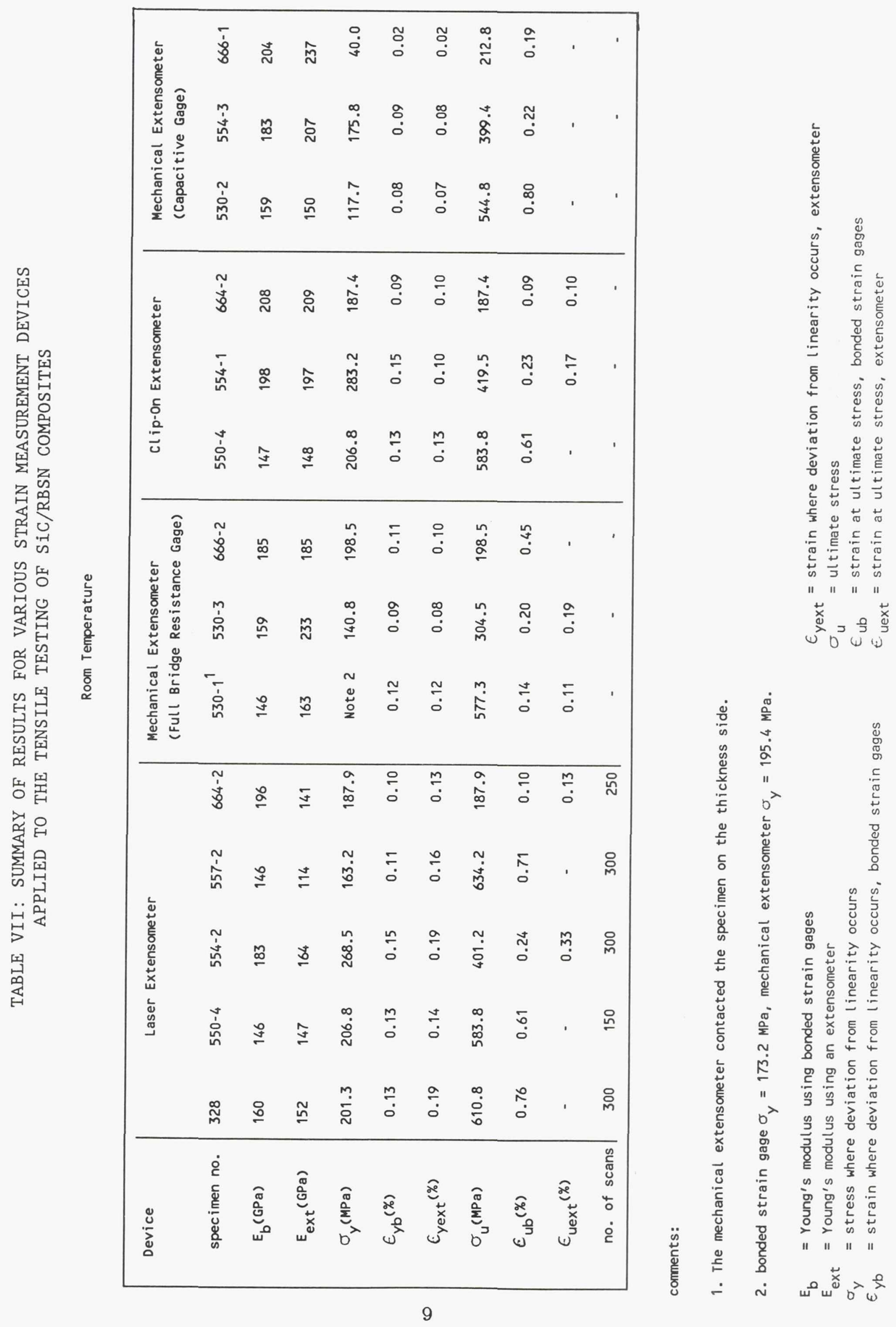




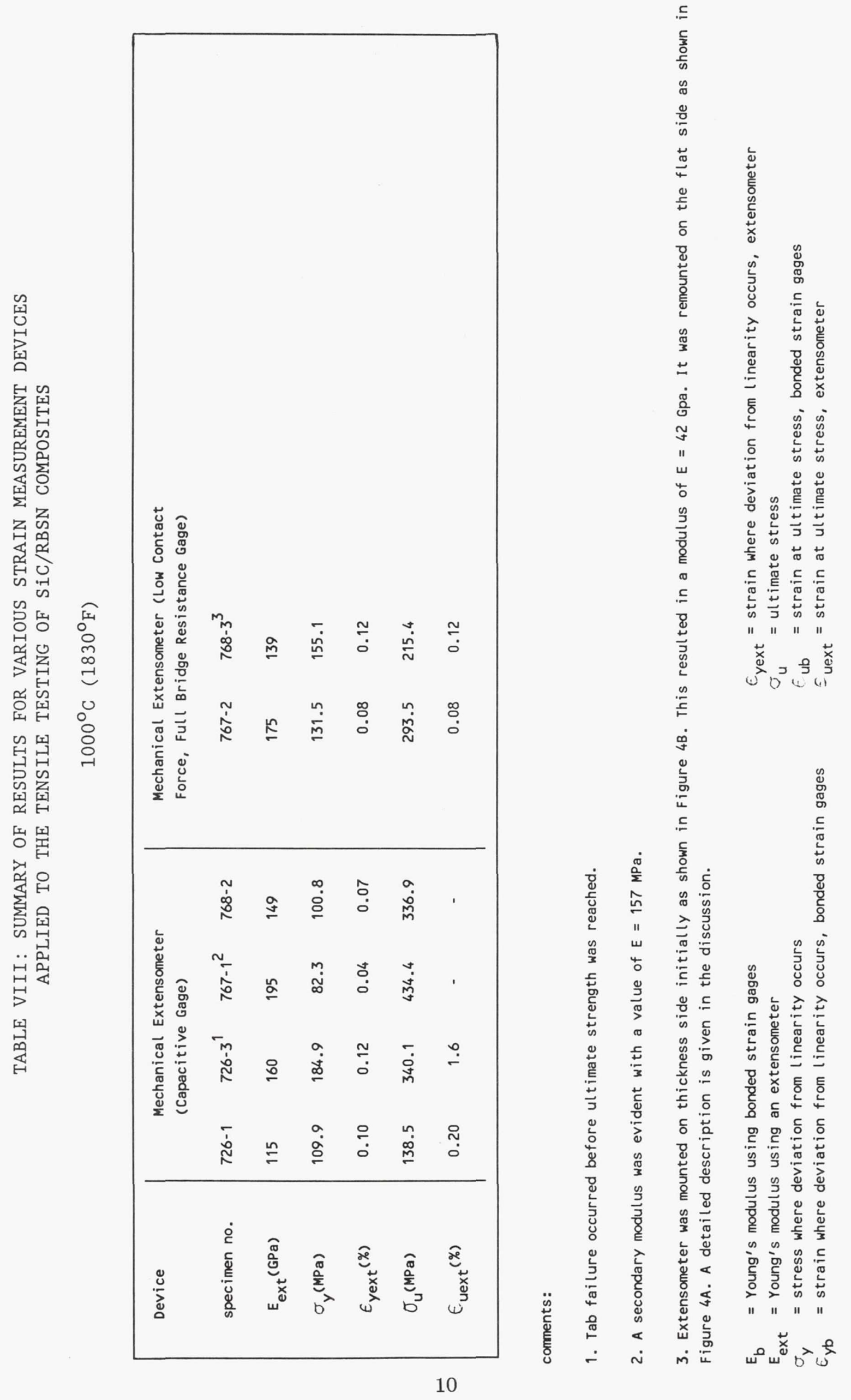


Once significant matrix cracking was initiated the bonded resistance strain gage showed a slight decrease in strain output. This was due to matrix cracking which was remote from the strain gage. The local matrix to which the strain gage was bonded unloaded slightly. On the other hand, the clip-on gage showed an increase in strain output since the matrix cracking was occurring within its gage length. At one point the clip-on gage showed a jump in strain from 0.168 to 2.08 . In contrast, the bonded strain gage showed only a minor increase from 0.168 to $0.17 \%$. The matrix continued to be strained which was shown by the bonded strain gage output. The clip-on gage had a major crack through the matrix within its gage length resulting in the large increase in strain output. The stress/strain plots can be observed in Figure 6. For specimen number 554-1 the clip-on gage slipped upon mounting the test coupon in the grips or gage on to the specimen because it had a constant offset relative to the bonded strain gage output from the onset of the test. The test with specimen number 664-2 showed nearly identical results from the bonded strain gage and the clipon gage.

4. Mechanical Extensometer, Full Bridge Resistance Gage, Room Temperature

The mechanical extensometer with the full bridge resistance gage exhibited slippage. This may have been due to the dulled blades of the quartz rods. The test with specimen number 530-3 was conducted with the contact force reduced from the recommended 550 grams per rod since the extensometer was placed on the weak axis of the test coupon (Fig. 4A). The result was a deviation on the linear portion of the stress/strain curve from the bonded strain gage output. The shift occurred early in the stress/strain curve at about 218 of the stress where deviation from linearity ensued.

The test with specimen number 530-1 had the extensometer rods mounted on the through-the-thickness edge of the test coupon (Fig. 4B). As noted earlier, the specimens were not treated in any way after they were cut from their panels. The edges have exposed fibers resulting in a rough contact surface for the extensometers. The data in Table VII shows that the mechanical extensometer did not record the first matrix crack at the same time as the bonded strain gages. The modulus calculated from the mechanical extensometer was $11 \%$ lower than the modulus that was derived from the bonded strain gage. Once matrix cracking was initiated the extensometer slipped enough to show a near zero strain level. We believe the exposed fibers on the edge of the specimen were not being strained as much as the majority of the test coupon. The fibers may have been debonded from the matrix and pulled apart in bundles leaving a poor contact surface for extensometer rods.

5. Capacitive Mechanical Extensometer, Room Temperature and $1000^{\circ} \mathrm{C}$ $\left(1830^{\circ} \mathrm{F}\right)$

Table VII contains the results from room temperature tensile tests using the capacitive mechanical extensometer. These results are also tabulated with the data from the bonded resistance strain gages.

Table VIII shows high temperature data using the capacitive mechanical extensometer. The specimen gage section temperature was held at approximately $1000^{\circ} \mathrm{C}$ $\left(1830^{\circ} \mathrm{F}\right)$ during all tests. All the tests with the capacitive mechanical extensometer had the extensometer mounted on the flat side of the specimen as illustrated in Figure 
4A.

The capacitive mechanical extensometer showed a very clean output signal with the room temperature tests. Referring to Table VII the test with specimen number 666-1 had the extensometer applied with a force of approximately 678 of the manufacturer's recommendation. The result was that the extensometer slipped once matrix cracking was initiated. The strain signal output dropped to near zero. The modulus that was derived from the extensometer output was $16 \%$ higher than the modulus that was derived from the bonded strain gage.

Specimen number 530-2 exhibited considerable fiber pullout after first matrix cracking. The bonded strain gage showed a gradual increase in strain after matrix cracking was initiated. The strain showed a decrease at about $41 \%$ of the ultimate stress. We believe the matrix to which the strain gage was bonded was being unloaded as fiber/matrix debonding was taking place. As a result, the matrix was starting to float freely on the fibers. In contrast, the mechanical extensometer showed a major increase in strain after matrix cracking was initiated. The stress/strain plot (Fig. 7) showed an elastic and nearly perfectly plastic type of curve. The specimen was pulling apart within the gage section of the extensometer. This showed the effects of different gage lengths.

The test with specimen number 554-3 showed reasonably good correlation between the bonded strain gage and the mechanical extensometer. Although, the moduli showed a $13 \%$ discrepancy between the bonded strain gage and mechanical extensometer. The matrix under one of the extensometer rods disintegrated once significant matrix cracking had taken place. This left the rod in contact with the rough surface of the fiber layer. The extensometer showed a sharp increase in strain as the specimen continued elongating.
Concurrently the bonded strain gage output showed a stress/strain curve with a slope only slightly less than the modulus within the elastic region.

A few specimens were tested at approximately $1000^{\circ} \mathrm{C}\left(1830^{\circ} \mathrm{F}\right)$ using the capacitive mechanical extensometer to measure the strain. Table VIII shows the material properties which were calculated from the test results. Noise was increased slightly in the strain signal. The signal oscillated within a strain range of approximately 0.0038 (Fig. 8). Specimen number 726-1 was taken to $1000^{\circ} \mathrm{C}\left(1830^{\circ} \mathrm{F}\right)$ once prior to this test. The first test exhibited problems with the tabs debonding due to the high temperatures. The second test showed a reasonably good stress/strain curve. The specimen showed lower values than expected but this is believed to be due to material effects and not due to the strain measuring device.

Specimen number 726-3 showed good results. The stress/strain plot is illustrated in Figure 8. However, tab failure occurred just before the ultimate strength was reached.

The test with specimen number 767-1 showed good results also. The properties showed negligible degradation relative to room temperature data. A secondary modulus or second linear region was also evident not unlike what has been witnessed in many of the room temperature tests. The strain at the ultimate strength exceeded the maximum strain limit of the extensometer. As a result, only the load was recorded for the ultimate strength.

In the process of trying different tabs, specimen number 768-2 had aluminum tabs. The specimen was delaminated under the tabs. The mechanical extensometer showed acceptable results. Unfortunately, the extensometer rods bottomed out in the furnace port before the ultimate strength was reached. 
6. Low Contact Force, Full Bridge Resistance Mechanical Extensometer, $1000^{\circ} \mathrm{C}\left(1830^{\circ} \mathrm{F}\right)$

All the tests with the low contact force extensometer with the Wheatstone bridge were conducted with specimen gage section temperatures of $1000^{\circ} \mathrm{C}\left(1830^{\circ} \mathrm{F}\right)$. This was due to the limited availability of the SiC/RBSN composites and time constraints. The high temperature mechanical properties are presented in Table VIII. The extensometer was mounted on the flat side of the specimen as illustrated in Figure 4A unless otherwise noted in the table.

The test with specimen number 767-2 exhibited a significant amount of noise in the strain output with the specimen at $1000^{\circ} \mathrm{C}\left(1830^{\circ} \mathrm{F}\right)$. This can be observed in Figure 9. The strain output oscillated by \pm 0.01 \& about the modulus within the linear region of the stress/strain curve. We believe this was due to turbulence around the alumina extensometer rods. The air turbulence causes differential thermal expansion from one side to the other side of the rods. The extensometer output went off the scale shortly after first matrix cracking occurred. This was due to the rods slipping on the surface of the specimen. The extensometer was setup with each rod applying a 100 gram force on the surface of the specimen. The specimen properties for the initial linear region of the stress/strain curve were as expected. Table VIII presents these properties where the modulus was $175 \mathrm{GPa}\left(25.4 \times 10^{6}\right.$ psi), first matrix cracking at 131.5 $\mathrm{MPa}$ (19080 psi) at 0.08 \& strain.

In order to reduce the noise that was observed in the test with specimen number 767-2 more insulation was placed by the furnace openings. The test with specimen number 768-3 resulted in a quieter signal. This specimen initially had the extensometer rods mounted on the thickness side as shown in Figure 4B. This resulted in the strain output increasing at a much greater rate then usual during the experiment. The test was stopped before matrix cracking occurred. The force on the rods was increased from 100 grams per rod to 400 grams per rod. The next attempt gave a similar result. A modulus of $42 \mathrm{GPa}(6.1 \mathrm{x}$ $10^{6}$ psi) was calculated which is much too low for this material. Again the test was terminated before matrix cracking. We believe the rods followed exposed bundles of fibers which were free to pull out with the grips instead of straining. The extensometer rods were relocated to the flat side of the specimen as shown in Figure 4A. The contact force was reduced to 100 grams per rod. This resulted in a much more acceptable modulus value of $139 \mathrm{GPa}$ (20.2 $\left.210^{6} \mathrm{psi}\right)$. The extensometer output dropped to zero with first matrix cracking due to the rods slipping on the surface of the specimen.

7. Tabs and Gage Attachment

It was mentioned earlier that some of the tests had tab failures. This was finally overcome by modifying the mounting procedure after consulting with the manufacturer of the film adhesive. The aluminum tabs used for the high temperature tests caused specimen delamination to occur. The film adhesive used to bond the tabs to the specimens required heating to $177^{\circ} \mathrm{C}\left(350^{\circ} \mathrm{F}\right)$. Due to the different thermal expansion coefficients between the ceramic specimen and the aluminum tabs delamination of the specimen occurred upon cooling. This problem was subdued by using the more compliant graphite/polyimide tabs.

During the testing we gained experience with specimen preparation and the mounting of the various strain gages. The type of mounting required for these strain measurement systems may be a significant consideration depending on the accuracy required and the environ- 
ment the specimen is to be tested in.

Bonded strain gages require about a day of preparation. This includes bonding the gages to the specimen and soldering electrical leads to the gages. Calibration is accomplished electronically using the signal conditioners.

The laser extensometer used in these tests necessitated the bonding of flags to the specimen surface. This process takes approximately one day. The laser and receiver are mounted on rails and are permanently lined up with the specimen making it easy to set up a test once the flags are attached to the specimen. Problems were encountered in keeping the flags on the specimen for the high temperature tests. The smooth surface of the specimens and the significant difference in the thermal expansion coefficients of the alumina based adhesive and silicon based test coupons made flag retention on the specimen surface difficult. The flags dropped off either during the heating cycle or when a mild load was applied to the specimen once at temperature. Due to unacceptable room temperature results, the problems with flag retention, and the lack of specimens, we did not conduct high temperature tests with the laser extensometer. Additional research is being conducted elsewhere in optimizing this system for high temperature tensile testing (ref. 12). Future work will include trying different adhesives for the flags and applying the system to measure strain in a tensile creep test. Changing the flag material will be considered also. Hanging flags, the type used at the National Institute of Standards and Technology (ref. 4), might be an alternative for tensile creep testing. However, static tensile testing of the SiC/RBSN type composites may prove to be difficult if not impossible with the hanging flags. This is due to the sudden release of energy as the composite fails causing the flags to slip.

The clip-on gage was by far the easiest to setup. A pin was used to hold the arms in place while the gage was mounted on the specimen. The pin was removed once the gage was mounted. Rubber bands were utilized to hold the gage to the specimen. The gage was electronically calibrated.

One of the mechanical extensometers was mounted on a sliding rail. The gage section was set using a stop and a micrometer. The extensometer was moved forward on its rail until it was just short of contacting the specimen. A horizontal micrometer was used to place the extensometer in contact with the specimen with the proper force. The stop and the micrometer used for setting the gage section were backed off leaving the extensometer free to track the specimen strain. This was a convenient technique for setting up the extensometer for testing. The other extensometers were a little less convenient to set up with the specimen but were still relatively quick techniques. The gage sections with these extensometers were set while the rods were in contact with the specimen. All the mechanical extensometers were manually calibrated by placing a fixed displacement on the rods and setting the gain for the desired output. The extensometer with the silicon carbide rods exhibited slightly less noise than the ones with the alumina rods during the high temperature tests.

\section{SUMMARY AND CONCLUSIONS}

It should be noted that the SiC/RBSN composites may present unique properties relative to other materials such as metals or even monolithic ceramics. The flat surface was smooth. In addition, these tests had all the specimens uniaxially reinforced by large diameter $(140 \mu \mathrm{m})$ fibers. Failure character- 
istics can be changed considerably by varying the fiber architecture. The SiC/RBSN composite system, used for these tests, is still in the development stages. As a result, composite properties vary from panel to panel. To reiterate, the objective of these tests was to compare various strain measuring devices and not to generate CMC design data.

The ideal strain measuring device for the SiC/RBSN composite would measure an average strain in the fibers. This would be especially advantageous once significant matrix cracking has occurred. Unfortunate$1 y$, all the available real time strain measuring devices monitor strain at the surface of the specimen which consists of the matrix material. Some of the test results showed a significant difference in the ultimate strain values from the different strain measuring devices. The gages which were optimized for the SiC/RBSN composites showed reasonable correlation beyond the deviation from linearity. A quick summary of the advantages and disadvantages of each of the strain measuring devices used for these tests is presented in Table IX.

The light contact force extensometers did an acceptable job of tracking the strain in the SiC/RBSN composites. The knife edge on the ends of the rods are preferred over the $\mathrm{V}$-notch. It is strongly recommended that the ends of the rods be sharp for all tests. This is to prevent or at least minimize the chance of slipping on the surface of the specimen. The silicon carbide rods are favored for the high temperature tests which includes temperatures up to $1550^{\circ} \mathrm{C}\left(2820^{\circ} \mathrm{F}\right)$ in air for our system. For the SiC/RBSN composites, the rods should be mounted on the flat surface of the specimens as shown in Figure 4A.

The clip-on gage is a convenient gage to use for room temperature applications. It is not as labor and time intensive to mount this gage as some of the other strain measuring devices.

The laser extensometer is more applicable to tensile creep testing. It can be applied to static tensile testing, but the strain rate has to be kept very low. Our system still needs to be optimized. A technique needs to be devised for retaining flags on the RBSN matrix of our ceramic composite specimens for high temperature applications. Non longitudinal motions in the specimen will be monitored in an attempt to determine the source of the sinusoidal output from the laser extensometer.

All the strain measuring devices should be mounted on the flat side of the specimen as illustrated in Figure 4A. This is important when testing similar types of materials where the edges are rough like the ones used for these tests and where multiple fractures result in a significant release of energy.

In conclusion, the light contact extensometers will be utilized for our future high temperature tensile tests. The SiC rods with the straight knife edges will be used with this device. This combination offered the best performance in testing the SiC/RBSN composites at high temperatures.

For the room temperature tests we will continue using the bonded resistance strain gages. The gages are compact and allow us to monitor bending in the specimen.

\section{ACKNOWLEDGEMENTS}

Stephen B. Roush (Case Western Reserve University, Lewis Research Center) for preparing the samples and assisting in the laboratory with the tests.

Ramakrishna T. Bhatt (Propulsion Directorate, U.S. Army Aviation Research and Technology Activity, Lewis Research Center) for supplying ceramic composite samples.

Ronald M. Shinn (Sverdrup Technology, Inc., Lewis Research Center) for 
setting up one of the extensometers.

Christopher S. Burke (Sverdrup Technology, Inc., Lewis Research Center) for fabricating custom mounting hardware for one of the extensometers and assisting in the setup.

Earl R. Hanes (NASA Lewis Research Center) for his assistance in acquiring much of the equipment.

\section{REFERENCES}

1. Gyekenyesi, J. Z., and Hemann, J . H., "Optical Strain Measuring Techniques for High Temperature Tensile Testing," NASA Contractor Report 179637 .

2. Gyekenyesi, J. Z., and Hemann, J. H., "High Temperature Tensile Testing of Ceramic Composites," NASA Contractor Report 180888.

3. Starrett, H. S., "High Temperature Test Methods," Presented at Composites Testing Methodology Workshop, February 8, 1990, National Institute of Standards and Technology, Gaithersburg, Maryland.

4. Wiederhorn, S. M., Carro11, D. F., Chuang, T. -J., and Roberts, D. E., "Standard Tensile Test Development," Ceramic Technology for Advanced Heat Engines Project Semiannual Progress Report for April Through September 1988. Oak Ridge National Laboratory report ORNL/TM11116 .

5. Hockey, B. J., Wiederhorn, S. M. , and Liu, W., "Tensile Creep of SiC Whisker Reinforced Silicon Nitride," Society of Automotive Engineers Proceedings of the Twenty-Seventh Automotive Technology Development Contractors' Coordination Meeting P230, Dearborn, MI, October 23-26, 1989.

6. Bhatt, R. T., "Influence of
Interfacial Shear Strength on the Mechanical Properties of SiC Fiber Reinforced Reaction-Bonded Silicon Nitride Matrix Composites," NASA Technical Memorandum 102462.

7. Bhatt, R. T. and Kiser, J. D., "Matrix Density Effects on the Mechanical Properties of SiC/RBSN Composites," NASA Technical Memorandum 103098.

8. Caputo, A. J., et. al., "Fiber Reinforced SiC Composites with Improved Mechanical Properties," American Ceramic Society Bulletin, V66, N2, 1987.

9. Jablonski, D. A. and Bhatt, R. T., "High Temperature Tensile Properties of Fiber Reinforced Reaction Bonded Silicon Nitride," Journal of Composites Technology \& Research, V12, N3, Fal1 1990, pp. $139-146$.

10. "1987 Annual Book of ASTM Standards, Space Simulation; Aerospace and Aircraft; High Modulus Fibers and Composites," V15.03. ASTM, Philadelphia, PA.

11. Sankar, J., Avra, V. S., Sinha, A., "Testing and Evaluation of Advanced Ceramics at High Temperature in Uniaxial Tension," Ceramic Technology for Advanced Heat Engines Project Semiannual Progress Report for October 1987 Through March 1988. Oak Ridge National Laboratory report ORNL/TM-10838.

12. Sankar, J., et. a1., "Testing and Evaluation of Advanced Ceramics at High Temperature in Uniaxial Tension," Ceramic Technology for Advanced Heat Engines Project Semiannual Progress Report for April 1989 Through September 1989. Oak Ridge National Laboratory report ORNL/TM-11489. 


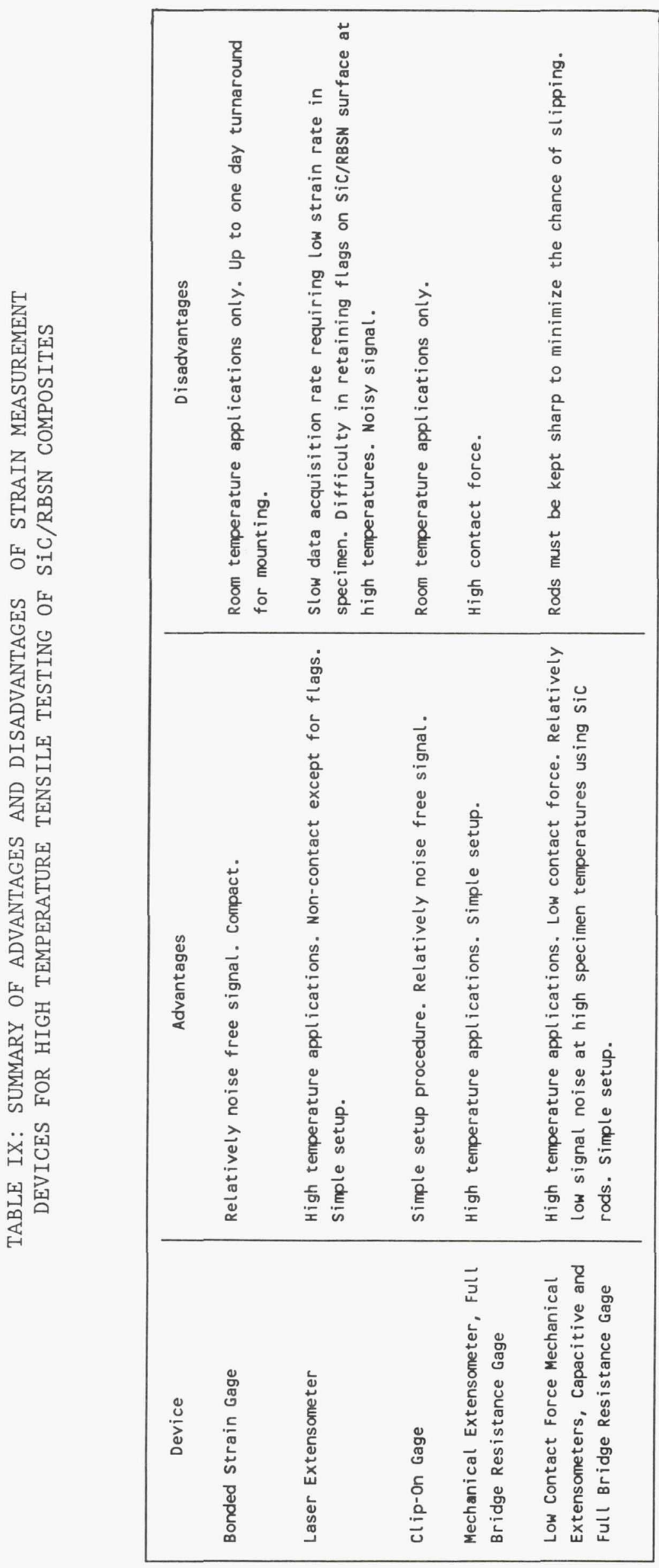




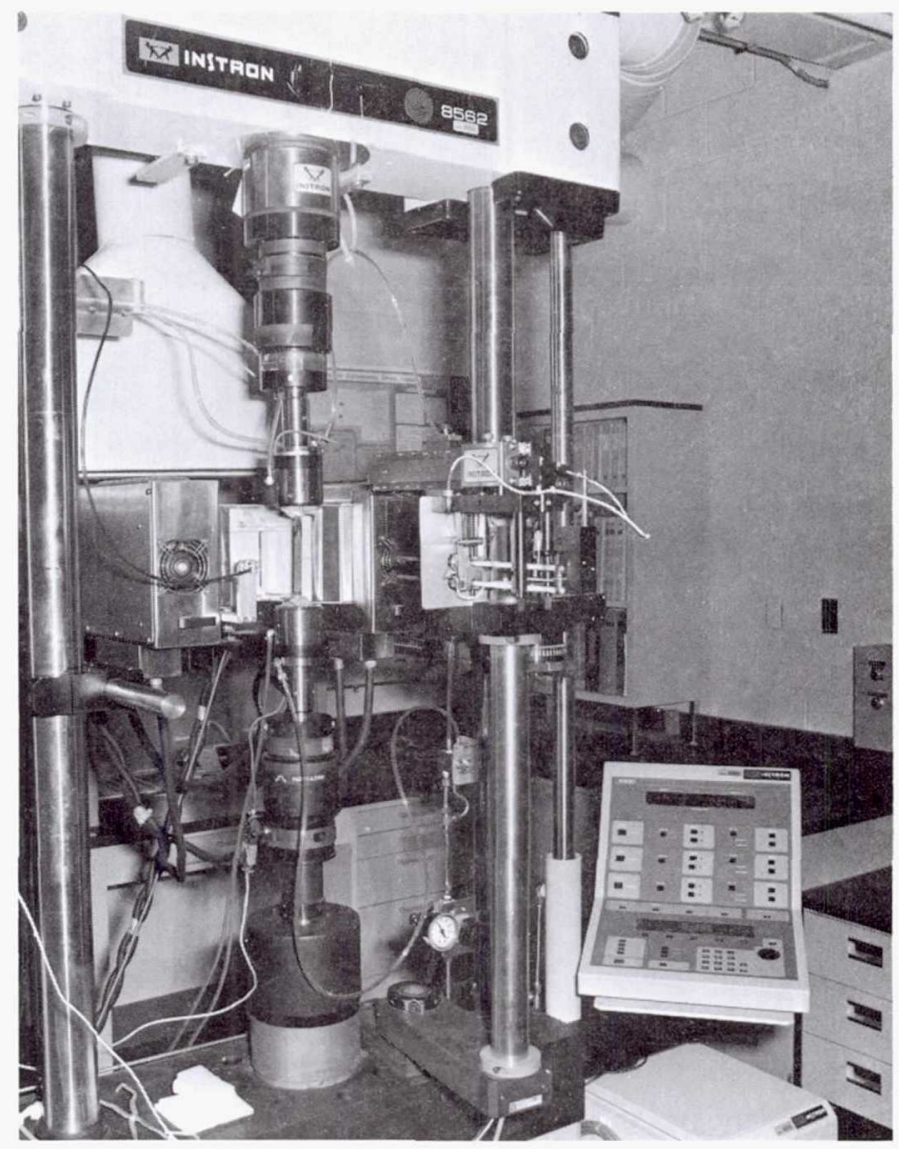

Figure 1. High temperature tensile testing system for ceramic composites.

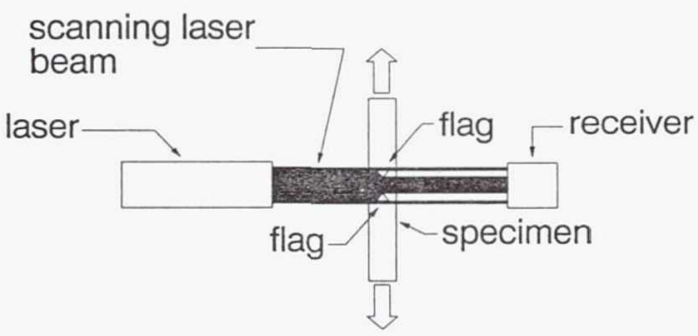

Figure 2. Schematic of optical laser extensometer. 

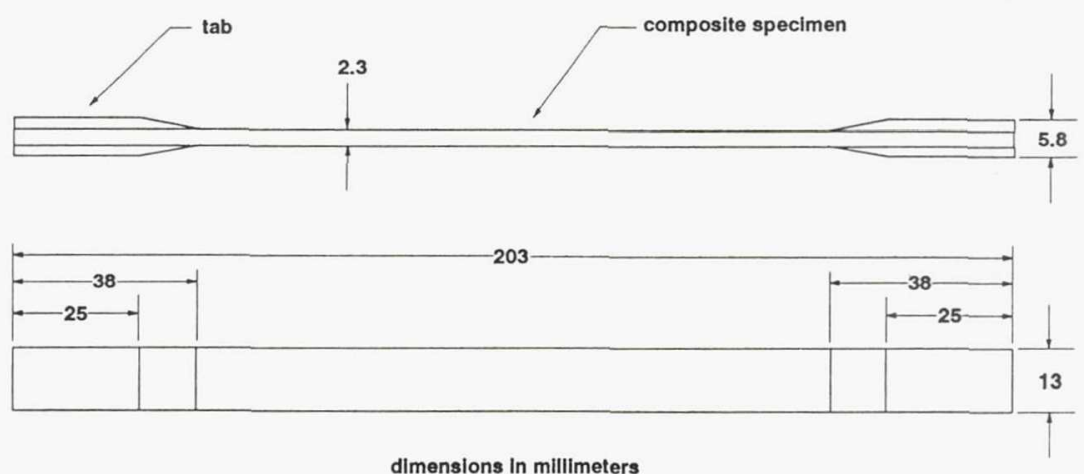

Figure 3. Tensile specimen with bonded tabs.

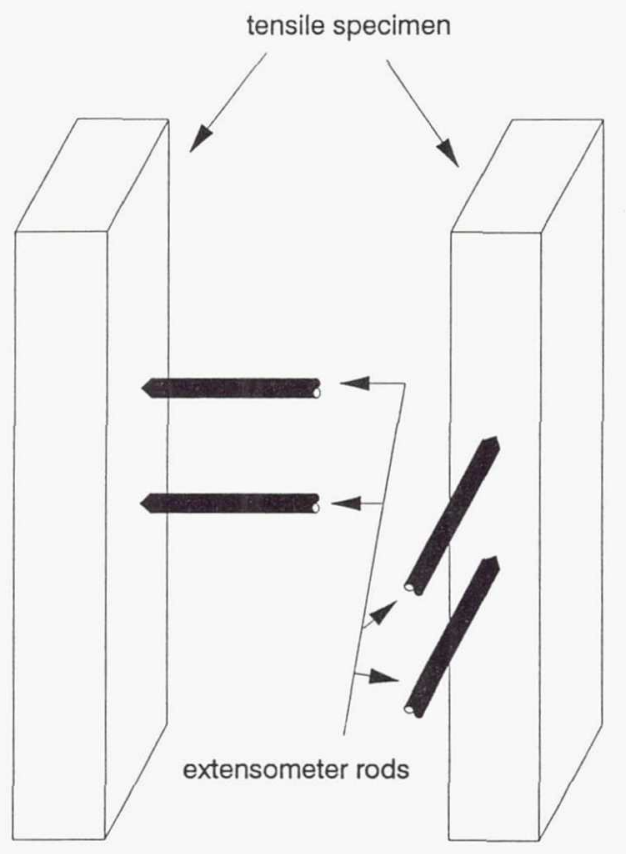

(A)
(B)

Figure 4. Extensometer rod location relative to tensile specimen.

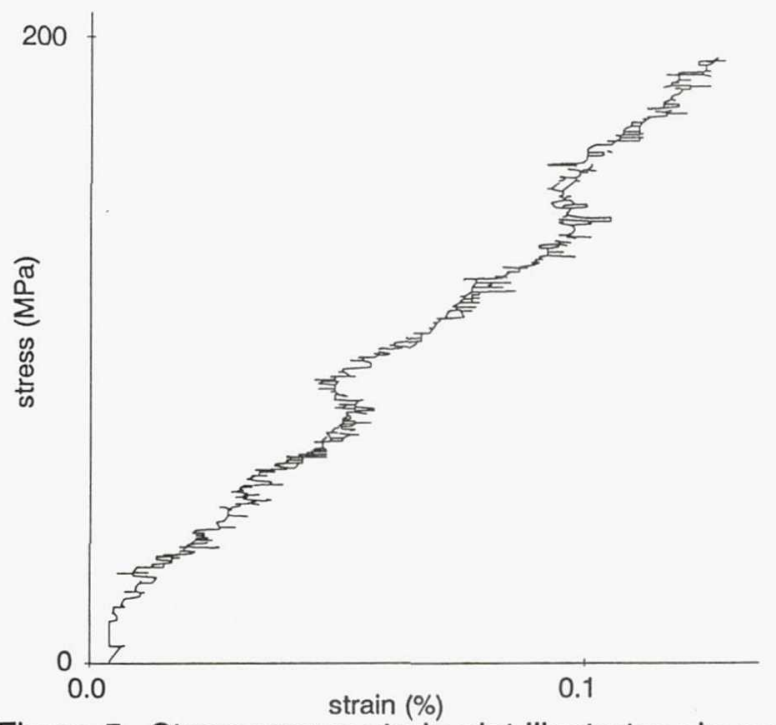

Figure 5. Stress versus strain plot illustrates sinusoidal motion of laser extensometer output. Test performed at room temperature. Specimen number 664-2. 


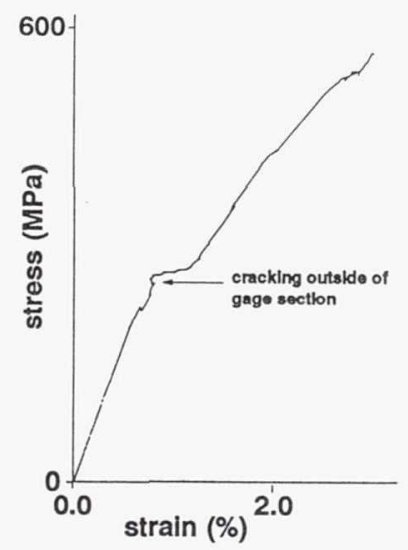

A) Using bonded resistance strain gage

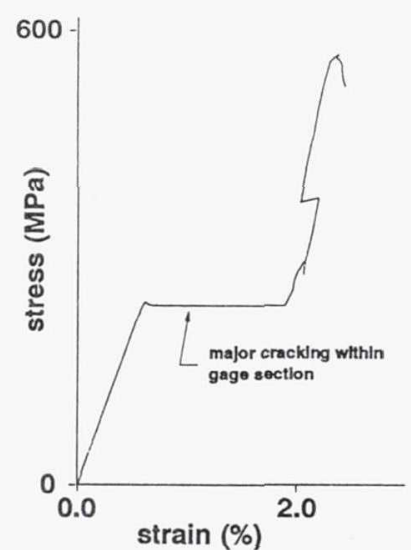

B) Using clip-on extensometer

Figure 6. Stress/strain curves using clip-on extensometer and bonded strain gage at room temperature. Plots illustrate differences in strain gage output with different gage lengths. Specimen number 550-4.

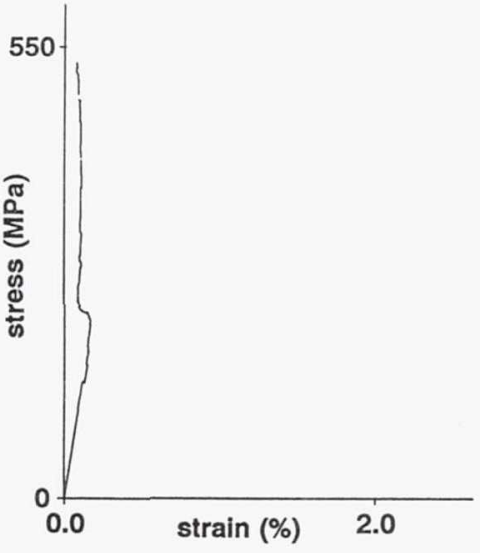

A) Using bonded resistance strain gage

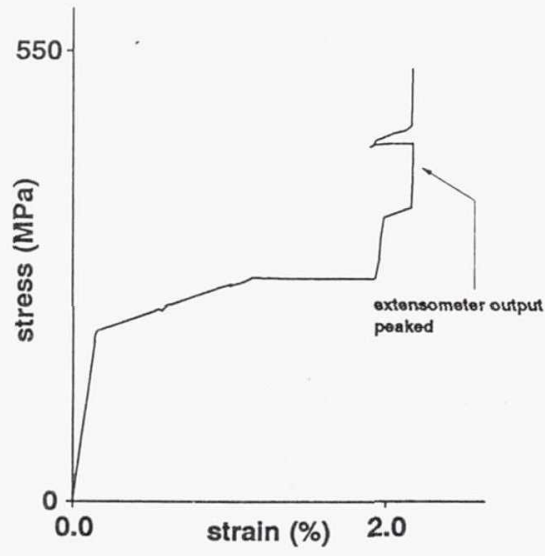

B) Using capacitive mechanical extensometer

Figure 7. Stress/strain curves using capacitive extensometer and bonded resistance strain gage at room temperature. Plots illustrate differences in strain gage outputs after deviation from linearity with different gage lengths. Specimen number 530-2. 


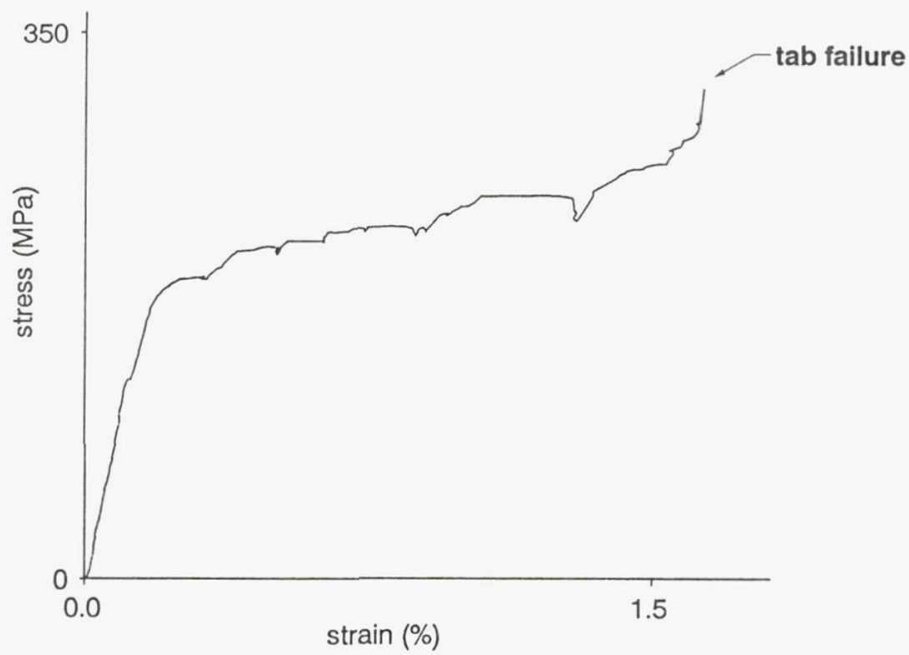

Figure 8. Stress versus strain plot illustrates sligthly increased noise of capacitive mechanical extensometer output at a specimen temperature of $1000^{\circ} \mathrm{C}$. Specimen number $726-3$.

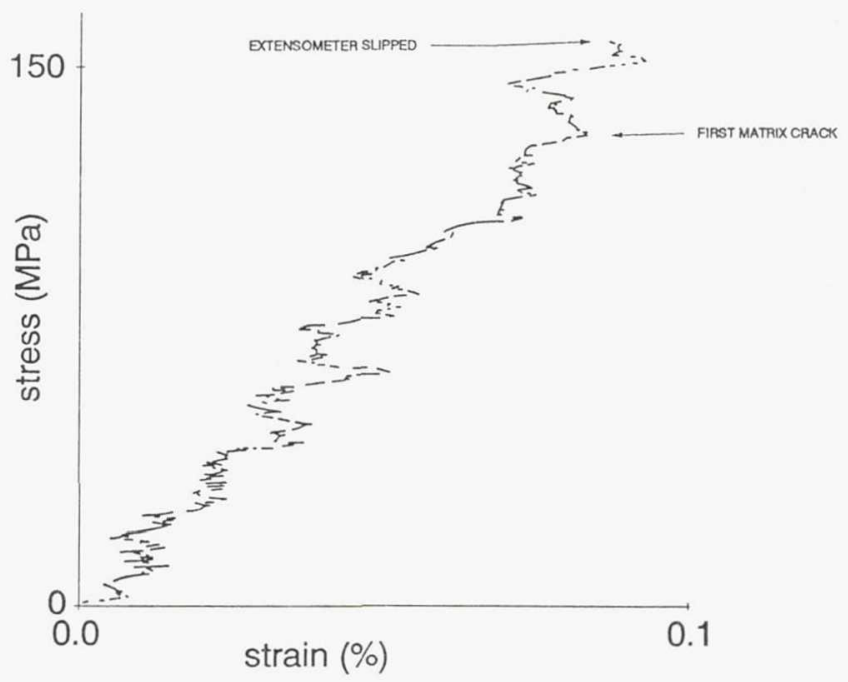

Figure 9. Stress/strain curve using low contact force extensometer at $1000^{\circ} \mathrm{C}$. Plot illustrates signal noise from extensometer. Specimen number 767-2. 
Public reporting burden for this collection of information is estimated to average 1 hour per response, including the time for reviewing instructions, searching existing data sources, gathering and maintaining the data needed, and completing and reviewing the collection of information. Send comments regarding this burden estimate or any other aspect of this collection of information, including suggestions for reducing this burden, to Washington Headquarters Services, Directorate for information Operations and Reports. 1215 Jefferson Davis Highway, Suite 1204, Arlington, VA 22202-4302, and to the Office of Management and Budget, Paperwork Reduction Project (0704-0188), Washington, DC 20503.

\begin{tabular}{|l|l|l|l|}
\hline 1. AGENCY USE ONLY (Leave blank) & $\begin{array}{c}\text { 2. REPORT DATE } \\
\text { November } 1991\end{array}$ & $\begin{array}{r}\text { 3. REPORT TYPE AND DATES COVERED } \\
\text { Technical Memorandum }\end{array}$ \\
\hline
\end{tabular}

4. TITLE AND SUBTITLE

An Evaluation of Strain Measuring Devices for Ceramic Composites

6. AUTHOR(S)

John Z. Gyekenyesi and Paul A. Bartolotta
5. FUNDING NUMBERS

$$
\text { WU-510-01-50 }
$$

\section{PERFORMING ORGANIZATION NAME(S) AND ADDRESS(ES)}

National Aeronautics and Space Administration

Lewis Research Center

Cleveland, Ohio 44135-3191
8. PERFORMING ORGANIZATION REPORT NUMBER

E-6704
9. SPONSORING/MONITORING AGENCY NAMES(S) AND ADDRESS(ES)

National Aeronautics and Space Administration

Washington, D.C. 20546-0001
10. SPONSORING/MONITORING AGENCY REPORT NUMBER

NASA TM - 105337

\section{SUPPLEMENTARY NOTES}

John Z. Gyekenyesi, Cleveland State University, Civil Engineering Department, Cleveland, Ohio 44115 and Resident Research Associate at NASA Lewis Research Center; Paul A. Bartolotta, NASA Lewis Research Center. Responsible person, John Z. Gyekenyesi, (216) 433-8184.

12a. DISTRIBUTION/AVAILABILITY STATEMENT 12b. DISTRIBUTION CODE

Unclassified - Unlimited

Subject Category 39

\section{ABSTRACT (Maximum 200 words)}

A series of tensile tests were conducted on SiC/RBSN composites using different methods of strain measurement. The tests were used to find the optimum strain sensing device for use with continuous fiber reinforced ceramic matrix composites in ambient and high temperature environments. Bonded resistance strain gages were found to offer excellent performance for room temperature tests. The clip-on gage offers the same performance but significantly less time is required for mounting it to the specimen. Low contact force extensometers track the strain with acceptable results at high specimen temperatures. Silicon carbide rods with knife edges are preferred. The edges must be kept sharp. The strain measuring devices should be mounted on the flat side of the specimen. This is in contrast to mounting on the rough thickness side.

\section{SUBJECT TERMS}

Ceramic matrix composites; Tensile tests; Strain gages; Extensometers; High temperature; Ceramics

\begin{tabular}{l|c}
\hline $\begin{array}{l}\text { 17. SECURITY CLASSIFICATION } \\
\text { OF REPORT }\end{array}$ & $\begin{array}{c}\text { 18. SECURITY CLASSIFICATION } \\
\text { OF THIS PAGE } \\
\text { Unclassified }\end{array}$ \\
\begin{tabular}{l} 
Unclassified \\
\hline
\end{tabular}
\end{tabular}

19. SECURITY CLASSIFICATION OF ABSTRACT Unclassified
15. NUMBER OF PAGES

16. PRICE CODE $\mathrm{AO} 3$

20. LIMITATION OF ABSTRACT Standard Form 298 (Rev. 2-89) Prescribed by ANSI Std. Z39-18 298-102 